\title{
Impact of temperature on Bacillus cereus spore germination in ultra-high temperature chocolate milk
}

\author{
1,*Ubong, A., ${ }^{1}$ New, C. Y., ${ }^{2}$ Chai, L.C., ${ }^{1}$ Nur Fatihah, A., ${ }^{1}$ Nur Hasria, K., ${ }^{3}$ Nishibuchi, M. \\ and ${ }^{1}$ Son, $\mathrm{R}$. \\ ${ }^{1}$ Department of Food Science, Faculty of Food Science and Technology, Universiti Putra Malaysia, 43400 \\ UPM Serdang, Selangor, Malaysia \\ ${ }^{2}$ Institute of Biological Sciences, Faculty of Science, University of Malaya, 50603 Kuala Lumpur, Malaysia \\ ${ }^{3}$ Center for Southeast Asian Studies, Kyoto University, Kyoto 606-8501, Japan
}

\author{
Article history: \\ Received: 12 May 2019 \\ Received in revised form: 14 \\ June 2019 \\ Accepted: 16 June 2019 \\ Available Online: 29 June \\ 2019
}

Keywords:

Bacillus cereus,

Spores,

UHT milk,

Germination,

Growth,

Temperature

DOI:

https://doi.org/10.26656/fr.2017.3(6).193

\begin{abstract}
Bacillus cereus spores are capable of surviving the harsh environment and more often, they cause great concern to the dairy industry. The current research was conducted to study the effect of temperature on germination and growth of $B$. cereus spores in UHT chocolate milk; the study was carried out at $8^{\circ} \mathrm{C}, 25^{\circ} \mathrm{C}$ and $35^{\circ} \mathrm{C}$ over a span of seven days. The results showed that no growth was observed at $8^{\circ} \mathrm{C}$. At $25^{\circ} \mathrm{C}$, a rapid increase in growth was observed as early as Day 1 , from an initial count of ten spores to $4.01 \log _{10}$ $\mathrm{CFU} / \mathrm{mL}$. Meanwhile, at $35^{\circ} \mathrm{C}$, the growth on Day 1 was more rapid in which the count promptly increased to $8.07 \log _{10} \mathrm{CFU} / \mathrm{mL}$. Analysis of graph trend showed that the number of vegetative cells decreased while the number of spores increased with incubation time due to nutrients exhaustion. This study fills up the data gap towards understanding the possible issues that might arise in the actual scenario and at the same time, suggests a suitable approach to minimize infection risk caused by B. cereus spores.
\end{abstract}

\section{Introduction}

Bacillus and Clostridium are the known bacterial genera that are capable of producing spores under hostile environment. They strive in the unfavourable conditions by producing endospores that protect the organism's main DNA and for replication purpose when the endospores germinate. An endospore is dormant, durable, and it does not carry out the metabolic reaction. Thanks to their durable nature, endospores are resistant to extreme heat, lack of water, exposure to various kind of toxic chemicals and radiation. Not to mention, they could sustain well without nutrients for a long period of time. It was previously described by Tortora et al. (2006) in their article that spores could persist in the environment for millions of years.

Bacillus cereus is a foodborne disease agent that is considered a high surveillance bacterium in the food manufacturing process, especially dairy products. The reintroduction of $B$. cereus in food is fairly low due to its non-competitive nature (Granum and Lund, 1997). However, the transfer of its endospores into food is the main transmission route of $B$. cereus as the endospores can be present anywhere due to its saprophytic life cycle; germinating, growing and sporulating within the environment (Vilain et al., 2006). From a clinical and food industry point of view, endospores are important due to their resistance towards many processes that normally kill vegetative cells. The processes include heating, freezing, desiccation, use of chemicals and radiation. When describing their extreme resistance, the endospores could survive sterilization of surgical equipment and in the same manner, surviving the heat treatment on food products, for example, pasteurisation and ultra-high heat treatment.

Endospore forms when there are triggers such as lack of key nutrients such as the carbon and nitrogen source. The process of endospore formation is known as sporulation or sporogenesis. Bacillus cereus sporogenesis begins with replication of chromosomal DNA and isolation of a small portion of cytoplasm by in growth of plasma membrane which eventually forms the forespore. Next, thick peptidoglycan layers will cover the forespore, followed by thick spore coat which responsible for endospore's resistance. At the end of sporogenesis, the original cell degrades, and endospore is released into the environment. It will eventually resume its vegetative state by a process known as germination when the environment becomes favourable again (Setlow, 2014). 
Essentially, there are two main categories in which microbial growth requirements can be divided into: physical and chemical. The physical categories include temperature, $\mathrm{pH}$ and osmotic pressure; chemical aspects include sources of carbon, nitrogen, sulphur, phosphorus, trace elements, oxygen and organic growth factors (Tortora et al., 2006). Temperature is the most implicated on microbial growth. It was noted by Camper et al. (1999), most regrowth events of the microbial population occur with the rise of temperature, which is an inevitable issue in Asian countries due to the climate.

Bacillus cereus is classified as mesophiles whereby their optimum temperature range falls within $30^{\circ} \mathrm{C}$ to $37^{\circ}$ C. Some strains were reported to grow well after cooking and cooling $\left(<50^{\circ} \mathrm{C}\right)$ (Granum and Lund, 1997; IDF, 2016). According to Lechner et al. (1998), B. weihenstephanensis was the psychrotolerant species within the $B$. cereus group due to its ability to grow below $7^{\circ} \mathrm{C}$, identified via its specific signature sequences in $16 \mathrm{~S}$ rRNA and cold-shock protein genes. In addition, depending on genetics, there are some B. cereus strains that have the ability to grow below $4{ }^{\circ} \mathrm{C}$ (IDF, 2016).

Despite that, there are contributing factors aforementioned which may affect the growth rate of $B$. cereus population. This present study will investigate the impact of temperature on the germination of $B$. cereus spores in UHT chocolate milk. The study focused on the $B$. cereus endospores as UHT is a process designed to destroy almost all vegetative cells of microorganism present in the sample product but unable to inactivate endospores.

\section{Materials and methods}

\subsection{Bacterial strain preparation}

Bacillus cereus ATCC 33019 strain used in this study was obtained from the American Type Culture Collection (Rockville, MD, USA). Bacillus cereus was revived and stored in glycerol stocks. From the glycerol stock, a loopful of B. cereus ATCC 33019 was inoculated into Tryptic Soy Broth (TSB) and incubated at $37^{\circ} \mathrm{C}$ for $24 \mathrm{hrs}$.

\subsection{Preparation of spore suspension}

Preparation of spore suspension was done according to the method described by te Giffel et al. (1995) with modifications according to Rukayadi et al. (2009). Sporulation was achieved by inoculating a 24-hour culture of $B$. cereus in TSB onto nutrient agar. The culture was incubated at $30^{\circ} \mathrm{C}$ for a week. After oneweek incubation, spores were washed from agar surface with sterile distilled water and collected in a $15 \mathrm{~mL}$ centrifuge tube. The suspension was centrifuged at 2000 $\mathrm{x} g$ for 20 mins and the supernatant was discarded. Following that, the pellet was washed three times and resuspended with sterile distilled water. In order to destroy vegetative cells, the spore suspension was subjected to heat shock of $80^{\circ} \mathrm{C}$ for 15 mins. The number of spores was determined using the plate count method using plate count agar. The prepared spore suspension was used immediately in this study.

\subsection{Spore germination study}

A total of two packs of sterile UHT chocolate milk were used in this study. A pack was spiked with approximately 10 spores $/ \mathrm{ml}$ using a sterile syringe, following that, the punctured hole was sealed using hot glue. Another pack was kept sterile and served as control. The UHT chocolate milk packs were incubated for 7 days at $8^{\circ} \mathrm{C}, 25^{\circ} \mathrm{C}$ and $35^{\circ} \mathrm{C} ; 8^{\circ} \mathrm{C}$ - to simulate milk that were kept in refrigerator, $25^{\circ} \mathrm{C}-$ to simulate the packs being kept at room temperature on retail stores' display shelves and $35^{\circ} \mathrm{C}-$ to simulate temperature abuse.

To count vegetative cells and spores' growth after 24 hrs, $1 \mathrm{~mL}$ of UHT chocolate milk from each pack was serially diluted with sterile distilled water and plated onto plate count agar. For spores' growth, one $\mathrm{ml}$ of UHT chocolate milk was subjected to a heat shock of $80^{\circ} \mathrm{C}$ for 15 mins. Following that, serial dilution for heatshocked chocolate milk was performed as previously mentioned. Plate count agars were then incubated at $37^{\circ}$ $\mathrm{C}$ for 15 hrs. Bacillus cereus colonies were counted using colony counter (Galaxy 230 Colony Counter, Taiwan). Spores germination were analysed for every 24 hrs for seven days.

\section{Results and discussion}

At the beginning of the study, UHT chocolate milk was first subjected to milk sterility check. One ml aliquot from UHT chocolate milk was added to $9 \mathrm{~mL}$ TSB and the solution was mixed thoroughly using vortex. The mixture was incubated at $37^{\circ} \mathrm{C}$ for $48 \mathrm{hrs}$. After 48 hrs incubation, the mixture was observed for sterility validation; the presence of foul odour, curding and changes in chocolate milk colour. For all samples purchased, no spoilage was observed.

The study was carried out at three different temperatures; (1) at refrigeration temperature to simulate the milk being placed in household refrigerators; (2) at room temperature to simulate the room temperature condition in which the milk was being displayed at airconditioned retail stores and; (3) at a temperature when the milk is placed under non-air-conditioned storage places where the milk could be subjected to temperature 
abuse. Figures 1 and 2 show the germination and growth of $B$. cereus spores within the span of seven days. Bacillus cereus' growth can be divided into two parts: (1) growth of vegetative cells and (2) number of spores formed during the whole incubation time.

At $8^{\circ} \mathrm{C}$, there was no growth observed for seven days of study for both spores and vegetative cells. Figure 1 shows a constant number of spores spiked From Day 1 until Day 7. The number of spores remained constant. Sensory evaluations were performed on chocolate milk; milk texture was smooth as no curding observed. Milk pack was not bloated and there was no foul smell detected.

In the earlier stage of analysis for temperature $25^{\circ} \mathrm{C}$ (Figure 2), vegetative cells showed a rapid increase in growth on Day 1 , from 10 spores to $4.01 \log _{10} \mathrm{CFU} /$ $\mathrm{mL}$ and subsequently doubled on Day 2 ( $8.42 \log _{10} \mathrm{CFU} /$ $\mathrm{mL}$ ). Throughout Day 3 to Day 7 , the growth began to decrease slowly in number (from $8.47 \log _{10} \mathrm{CFU} / \mathrm{mL}$ to $7.30 \log _{10} \mathrm{CFU} / \mathrm{mL}$ ) as it was reaching stationary phase. Simultaneously, the number of spores began to increase starting on Day $3\left(4.43 \log _{10} \mathrm{CFU} / \mathrm{mL}\right)$ and gradually increased in number throughout Day 4, Day 5 and Day 6 (4.77 $\log _{10} \mathrm{CFU} / \mathrm{mL}, 5.03 \log _{10} \mathrm{CFU} / \mathrm{mL}$ and $5.44 \log _{10}$ $\mathrm{CFU} / \mathrm{mL}$ respectively). A number of spores began to decrease on Day $7\left(5.34 \log _{10} \mathrm{CFU} / \mathrm{mL}\right)$ as it reached the stationary phase. Curding was observed in milk texture; milk pack showed bloating starting Day 1 and there was foul smell detected.

Figure 3 shows the results for analysis on temperature $35^{\circ} \mathrm{C}$. Vegetative cells showed rapid growth as early as Day 1, starting from 10 spores and promptly increased to $8.07 \log _{10} \mathrm{CFU} / \mathrm{mL}$. The count increased slightly to $8.24 \log _{10} \mathrm{CFU} / \mathrm{mL}$ on Day 2 . However, the number of vegetative cells started to decline gradually on Day 3 (7.49 $\log _{10}$ CFU/mL) and Day 4 (7.45 $\log _{10}$ CFU/ $\mathrm{mL})$. They slightly increased on Day $5\left(7.46 \log _{10} \mathrm{CFU} /\right.$ $\mathrm{mL})$ as well as Day $6\left(7.65 \log _{10} \mathrm{CFU} / \mathrm{mL}\right)$ and finally, they decrease again on Day $7\left(7.49 \log _{10} \mathrm{CFU} / \mathrm{mL}\right)$ as it reached stationary phase. The number of spores began to increase on Day $2\left(5.83 \log _{10} \mathrm{CFU} / \mathrm{mL}\right)$ and they continue to moderately increase on Day 3 throughout Day 7 (from $6.27 \log _{10} \mathrm{CFU} / \mathrm{mL}$ to $6.66 \log _{10} \mathrm{CFU} / \mathrm{mL}$ ). There was a very slight decrease of spore number on Day $5\left(6.20 \log _{10} \mathrm{CFU} / \mathrm{mL}\right)$ before they increase again on Day 6 to Day 7. Curding was also observed in milk texture; milk pack also showed bloating starting Day 1 and there was also foul smell detected.

At $8^{\circ} \mathrm{C}$, no spore germination and growth were detected during analysis, in which this temperature is distinctly not the optimum growth temperature for $B$. cereus. Hence, the milk remained unaltered. At the end of the analysis (Day 7), the milk was then transferred to $35^{\circ} \mathrm{C}$ incubator; spores resumed germination and growth

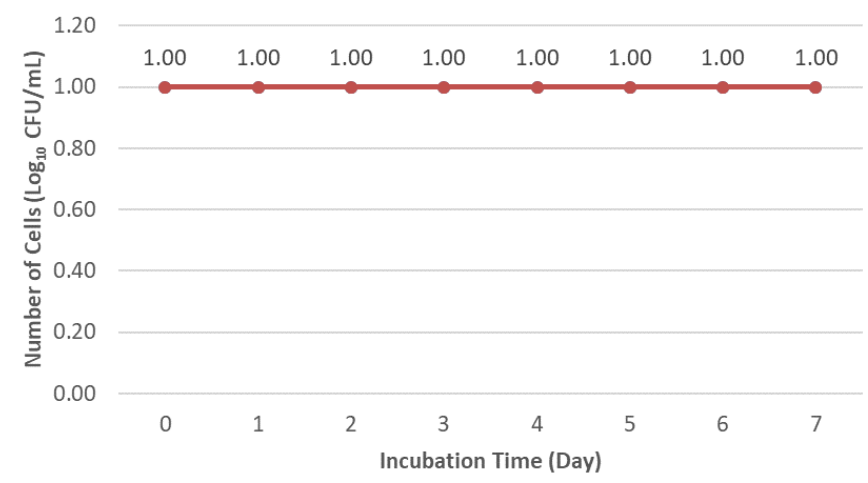

Figure 1. Growth curve at $8^{\circ} \mathrm{C}$ showing the growth of vegetative cells and spores both indicated with the red line in a seven-day study.

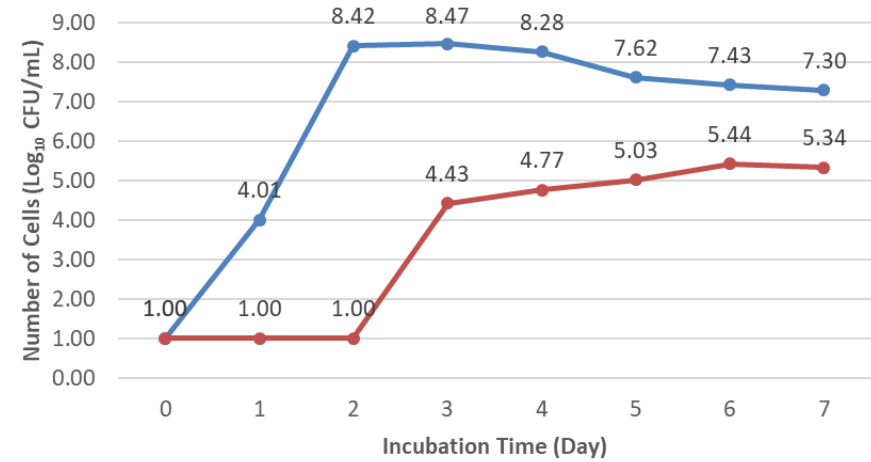

Figure 2. Growth curve at $25^{\circ} \mathrm{C}$ showing (1) germination and growth of vegetative cells indicated with the blue line and (2) formation of spores indicated with the red line in a seven-day study.

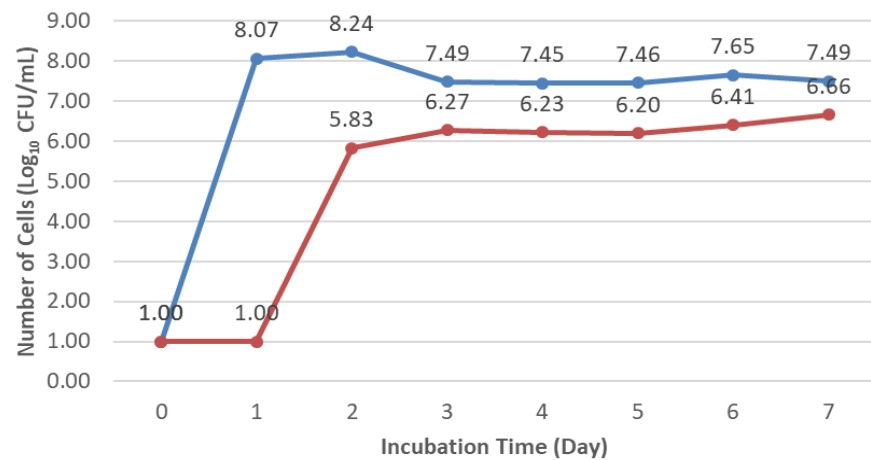

Figure 3. Growth curve at $35^{\circ} \mathrm{C}$ showing (1) germination and growth of vegetative cells indicated with the blue line and (2) formation of spores indicated with the red line in a seven-day study.

C 2019 The Authors. Published by Rynnye Lyan Resources 
as usual. According to Levinson and Hyatt (1970), the optimum for the spore germination lies between $28^{\circ} \mathrm{C}$ and $38^{\circ} \mathrm{C}$ which explained the immediate growth of $B$. cereus in the milk when it was placed at $35^{\circ} \mathrm{C}$. On the other hand, the growth of vegetative $B$. cereus in milk at the storage temperature of $25^{\circ} \mathrm{C}$ and $35^{\circ} \mathrm{C}$ was initiated from bacterial spores. In nature, spore germination is triggered by the presence of specific nutrients as the nutrients germinant will bind to spore-specific protein complexes in a stereospecific manner in the inner membrane (Setlow, 2014). In the present study, although nutrients were present, no spore germination was observed at $8^{\circ} \mathrm{C}$ which could infer the influence of temperature on spore germination.

There is no evidence for discontinuities in the response of spores to temperature (Levinson and Hyatt, 1970). But, the rate and extent of germination (Vas and Proszt, 1957; O'Connor and Halvorson, 1961; Vary and Halvorson, 1965) and the lag period preceding germination (Keynan and Halvorson, 1962; Vary and Halvorson, 1965) are influenced by the germination temperature. It is a typical magnitude of enzymic reactions (Levinson and Hyatt, 1970). In other words, when the surrounding temperature is near the optimum temperature, the germination process will be triggered when the enzymic reaction is activated.

The growth of vegetative $B$. cereus at $25^{\circ} \mathrm{C}$ was slower compared to the growth at $35^{\circ} \mathrm{C}$ when it was not within the optimum growth temperature. Due to the slow growth, the abundance of nutrients present in the milk was slowly consumed by the bacteria (Lafarge et al., 2004; Ray and Bhunia, 2008; de Oliveira et al., 2014) resulting in no production of spores in Days 1 and 2 of storage. In comparison, the vegetative $B$. cereus grew rapidly at $35^{\circ} \mathrm{C}$ and by Day 2 of storage, there was production of spores when the nutrients depleted. At the same day of storage, the maximum growth of vegetative $B$. cereus was achieved. When compared to the storage at $25^{\circ} \mathrm{C}$, the maximum growth was achieved at Day 3 . As the incubation time increased, the number of vegetative cells began to decrease gradually due to nutrient depletion. On the other hand, the number of spores began to increase as nutrients reduced and conditions became unfavourable for growth (Setlow, 2014). The trend of the graph shows that the number of vegetative cells decreased while the number of spores increased with incubation time, an inversely proportional relationship which indicates the survival mode of $B$. cereus.

It should be noted that the spore characteristics are greatly influenced by the different genetic of the $B$. cereus strains (Wiencek et al., 1990; Tauveron et al.,
2006; Faille et al., 2007). In addition, Setlow (2006) stated that the spore resistance and dormancy are due to both the unique spore components and spores' unique structure. If there are multiple contaminations of different strains of $B$. cereus spores, it may become a severe issue in decontamination. Notwithstanding, there were other studies which observed $B$. cereus activity such as its toxin production in lower temperature. What was interesting in their finding was, emetic $B$. cereus produces the highest amount of emetic toxin at lower temperatures; $12^{\circ} \mathrm{C}$ and $15^{\circ} \mathrm{C}$ (Finlay, 2000). In another related study, B. cereus toxin exhibit cytotoxicity at $15^{\circ}$ $\mathrm{C}$ and $8^{\circ} \mathrm{C}$ under aerated conditions (Christiansson et al., 1989). In other studies, psychrotrophic B. cereus was successfully isolated. They posed threat to public as they were capable of growing under low temperatures and contaminating chilled food (Dufrenne et al., 1994; Choma et al., 2000).

It is widely recognised that $B$. cereus spores are a major concern in food industry. Despite being infamous for its extremely durable endospores, they could also become superdormant spores. Superdormant spores are slow-to-germinate spores and could remain dormant in food by showing no sign of spoilage. They display an extremely long lag period which can last for possibly days, weeks or months (Ghosh and Setlow, 2009; Setlow, 2014). This brought up the concern that superdormant spores could persist in UHT equipment and will remain dormant even after the decontamination process. Although many studies on the model spore former, B. subtilis, which represents general conclusion for spores of other Bacillus species has been done previously, nothing is known about what is happening during this lag period (Setlow, 2014). However, it was stated that L-amino acids such as L-alanine, L-valine, and L-asparagine trigger germination of $B$. subtilis spores while D-amino acid, on the other hand, is inert (Gould, 1969; Atluri et al., 2005).

The present study simulated the influence of temperature on the germination of spores and growth rate of B. cereus in spore-contaminated UHT milk. In the real case scenario, the density of spore contamination in UHT milk may not be high, but the surrounding temperature, especially in the South East Asia region will trigger the germination of the spores and thus, the growth of $B$. cereus. Additionally, UHT milk is stored at room temperatures which increases the probability of $B$. cereus growth in them.

\section{Conclusion}

In a manner, this study gave us an idea of what might happen in the real scenarios by filling up the data 
gap. Extremely resistant surviving spores after sterilization treatment or recontamination could have eventually germinate due to nutrients from milk and ambient temperature that supports their growth. In the matter of surviving spores, routine cleaning for UHT equipment should be done from time to time. Apart from that, effective UHT temperature should be monitored to ensure that no spores could get through the sterilization process. Using the available knowledge, we could also suggest ways to minimize profit loss in companies which produce UHT milk. Additionally, this study also demonstrates milk as a potential medium for B. cereus infection.

\section{Acknowledgements}

This research is supported by the Fundamental Research Grant Scheme (FRGS) of the Ministry of Higher Education (MOHE), Malaysia (01-01-182015FR).

\section{References}

Atluri, S., Ragkousi, K., Cortezzo, D.E. and Setlow. (2005). Cooperativity Between Different Nutrient Receptors in Germination of Spores of Bacillus subtilis and Reduction of This Cooperativity by Alterations in the GerB Receptor. Journal of Bacteriology, 188(1), 28-36. https://doi.org/10.1128/ JB.188.1.28-36.2006

Camper, A., Burr, M., Ellis, B., Butterfield, P. and Abernathy, C. (1999). Development and structure of drinking water biofilms and techniques for their study. Journal of Applied Microbiology Symposium Supplement, 85(S1), 1S-12S. https://doi.org/10.1111/ j.1365-2672.1998.tb05277.x

Choma, C., Guinebretière, M.H., Carlin, F., Schmitt, P., Velge, P., Granum, P.E. and Nguyen-The, C. (2000). Prevalence, characterization and growth of Bacillus cereus in commercial cooked chilled foods containing vegetables. Journal of Applied Microbiology, 88(4), 617-625. https:// doi.org/10.1046/j.1365-2672.2000.00998.x

Christiansson, A., Naidu, S.A., Nilsson, I., Wardstorm, T. and Pettersson, H. (1989). Toxin Production by Bacillus cereus Dairy Isolates in Milk at Low Temperatures. Applied and Environmental Microbiology, 55(10), 2595-2600.

de Oliveira, G.B., Favarin, L., Luchese, R.H. and McIntosh, D. (2014). Psychrotrophic bacteria in milk: How much do we really know?. Brazilian Journal of Microbiology, 46(2), 313-321. https:// doi.org/10.1590/S1517-838246220130963

Dufrenne, J., Bijwaard, M., te Giffel, M., Beumer, R. and
Notermans, S. (1994). Characteristics of some psychrotrophic Bacillus cereus isolates. Food Microbiology, 27(2-3), 175-183. https:// doi.org/10.1016/0168-1605(94)00163-Z

Faille, C., Tauveron, G., Le Gentil-Lelievre, C. and Slomianny, C. (2007). Occurrence of Bacillus cereus spores with a damaged exosporium: consequences on the spore adhesion on surfaces of food processing lines. Journal of Food Protection, 70(10), 23462353. https://doi.org/10.4315/0362-028X-70.10.2346

Finlay, W.J.J., Logan, N.A. and Suntherland, A.D. (2000). Bacillus cereus produces most emetic toxin at lower temperatures. Letters in Applied Microbiology, 31(5), 385-389.

Ghosh, S. and Setlow, P. (2009). The preparation, germination properties and stability of superdormant spores of Bacillus cereus. Journal of Applied Microbiology, 108(2), 582-590. https:// doi.org/10.1111/j.1365-2672.2009.04442.x

Gould, G.W. (1969). Germination. In Gould G.W. and Hurst, A. (Eds.). The Bacterial Spore., p. 397-444. London, United Kingdom: Academic Press.

Granum, P.E. and Lund, T. (1997). Mini Review: Bacillus cereus and its food poisoning toxin. FEMS Microbiology Letters, 157(2), 223-228. https:// doi.org/10.1111/j.1574-6968.1997.tb12776.x

International Dairy Federation (IDF). (2016). Bacillus cereus in milk and dairy products. Retrieved from IDF website: https://www.fil-idf.org/wp-content/ uploads/2016/12/Bacillus-cereus-in-Milk-and-DairyProducts.pdf.

Keynan, A. and Halvorson, H.O. (1962). Calcium Dipicolinic Acid-Induced Germination of Bacillus cereus Spores. Journal of Bacteriology, 83, 100-105.

Lafarge, V., Ogier, J., Girard, V., Maladen, V., Leveau, J., Gruss, A. and Delacroix-Buchet, A. (2004). Raw Cow Milk Bacterial Population Shifts Attributable to Refrigeration. Applied and Environmental Microbiology, 70(9), 5644-5650. https:// doi.org/10.1128/AEM.70.9.5644-5650.2004

Levinson, H.S. and Hyatt, M.T. (1970). Effects of Temperature on Activation, Germination and Outgrowth of Bacillus megaterium Spores. Journal of Bacteriology, 101, 58-64.

O'Connor, R.J. and Halvorson, H.O. (1961). L-Alanine Dehydrogenase: A Mechanism Controlling the Specificity of Amino Acid-Induced Germination of Bacillus Cereus Spores. Journal of Bacteriology, 82, 706-713.

Ray, B. and Bhunia, R. (2008). Fundamental Food Microbiology. $4^{\text {th }}$ ed., p. 35-41. Florida: CRC Press Taylor and Francis Group. 
Rukayadi, Y., Lee, K., Han, S., Kim, S. and Hwang, J.K. (2009). Antibacterial and sporicidal activity of macelignan isolated from nutmeg (Myristica fragrans Houtt.) against Bacillus cereus. Food Science and Biotechnology, 18(5), 1301-1304.

Setlow, P. (2014). Germination of Spores of Bacillus Species: What We Know and Do Not Know. Journal of Bacteriology, 196(7), 1297-1305. https:// doi.org/10.1128/JB.01455-13

Setlow, P. (2006). Spores of Bacillus subtilis: their resistance to radiation, heat and chemicals. Journal in Applied Microbiology, 101(3), 514-525. https:// doi.org/10.1111/j.1365-2672.2005.02736.x

te Giffel, M.C., Beumer, R.R., Hoekstra, J. and Rombouts, F.M. (1995). Germination of bacterial spores during sample preparation. Food Microbiology, 12, 327-332. https://doi.org/10.1016/ S0740-0020(95)80113-8

Tauveron, G., Slomianny, C., Henry, C. and Faille, C. (2006). Variability among Bacillus cereus strains in spore formation properties and influence on their ability to contaminate food surface equipment. International Journal of Food Microbiology, 110(3), 254-262. https://doi.org/10.1016/ j.ijfoodmicro.2006.04.027

Tortora, G.J., Funke, B.R. and Case, C.L. (2006). The Control of Microbial Growth. In Berriman, L. (Ed.) Microbiology an Introduction. $9^{\text {th }}$ ed., p. 187-213. California, USA: Pearson Benjamin Cummings, San Francisco.

Vary, J.C. and Halvorson, H.O. (1965). Kinetics of germination of Bacillus spores. Journal of Bacteriology, 89, 1340-1347.

Vas, K. and Proszt, G. (1957). Effect of temperature and hydrogen-ion concentration on the germination of spores of Bacillus cereus. Nature, 179, 1301-1302. https://doi.org/10.1038/1791301a0

Vilain, S., Luo, Y., Hildreth, M.B. and Brozel, V.S. (2006). Analysis of the life cycle of the soil saprophyte Bacillus cereus in liquid soil extract and in soil. Applied and Environmental Microbiology, 72 (7), 4970-4977. https://doi.org/10.1128/AEM.0307605

Wiencek, K.M., Klapes, N.A. and Foegeding, P.M. (1990). Hydrophobicity of Bacillus and Clostridium spores. Applied in Environmental Microbiology, 56, 2600-2605. 